\title{
OPTIMIZATION OF FASTENING CONSTRUCTION FOR THE PORTABLE TANKS
}

\author{
M. Jureczko*, A. Chwiendacz ${ }^{* *}$ \\ Abstract: The aim of the research presented in this article is optimization of support/fastening for \\ the portable tank which holds liquified gases. Two criteria were considered: ensuring a minimal construction \\ mass and a minimal production costs while strength conditions are fully met for subject of study.
}

Keywords: fastening construction, portable tanks, finite element method, MPGM

\section{Introduction}

Fastening construction which is important piece of improvement of transport process, are also used to capture the leaks from tanks. They allow to reduce negative influence of substances that can threaten the natural environment and even workers. It is important to reduce the risk of losing transported materials. Such a functionality does not take place in case of pallets prepared for barrels with liquid gases, because of high internal pressure. The most important property (Pawłowski, 2009) that describe fastening construction is maximum load that has to be maintained. The ones (pallets) used to place portable tank apart from requirement of stiffness have to go through a series of durability trials which evaluates its value under static load. Stresses that appears as effect of these test actions may lead to deformations of its original shape in points where tests are most intensive. Finally, forces that affect the construction changes positions of its parts and their deformation (Ashby, 2007).

\section{Design and optimization assumptions}

Optimization of fastening construction of portable tank for liquid gas considered simultaneously two criteria: ensure a minimal weight and minimal cost of implementation, and at the same time fulfill strength criterion included in relevant standards. Research takes following project variables: length, width and height of construction, sheet thickness, thickness of profiles. Research method and numerical calculations used weighted sum method (Jureczko, 2013 and Kim, 2005).

Strength conditions that applies to fastening constructions are included in EN 14208 "Transportable gas cylinders - specification for welded gas drums up to 3000 litre capacity for the transport of gases - Design and construction" and its equivalent approved by European Committee for Standardisation (CEN). According to them "portable tanks and their fastenings shall, under the maximum permissible load, be capable of absorbing the static force directed vertically downwards, which values is twice the MPGM (where MPGM means the sum of the tare mass of the portable tank and the heaviest load authorized for carriage) multiplied by the acceleration due to gravity. Under this force, the safety factor for steels having a clearly defined yield point should be equals 1.5 in relation to the guaranteed yield strength' (ADR 6.7.3.2.10, 2017)."

Mariola Jureczko, PhD. Eng: Silesian University of Technology, Institute of Theoretical and Applied Mechanics, Konarskiego Street 18 A/186; 44-100, Gliwice; PL, mjureczko@polsl.pl

** Artur Chwiendacz, Eng.: student Silesian University of Technology, Institute of Theoretical and Applied Mechanics, Konarskiego Street 18 A/186; 44-100, Gliwice; PL, 
Defining the cost of implementation of fastening construction, the both: labor and material costs were taken into account (e.g. welder work cost).

Taking into account the imposed conditions, the pallet construction is shown in Fig. 1a.
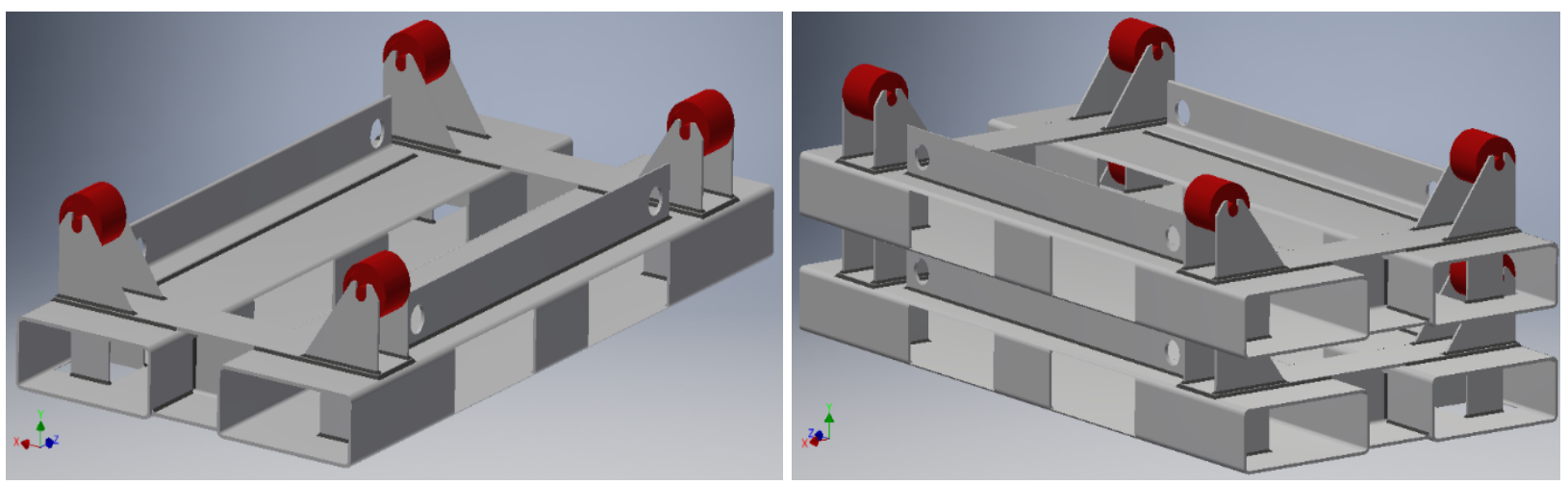

Fig. 1: CAD model of the fastening construction: a) single, b) multiple.

Palette was designed as inseparable construction made of profiles. Project include possibility of safe stacking of multiple platforms through use of grooves on the bottom of palette which blocks rollers and prevent spontaneous movements relative to each other. Block rollers have dimensions: diameter $85 \mathrm{~mm}$, width: $80 \mathrm{~mm}$, with polyurethane tread, where the shield is made of steel. Load capacity of single roll: $610 \mathrm{~kg}$. Rolls are placed in every of four support points of tank. Uneven brackets are handles for tension belts, additionally strengthening and stiffening construction increasing also its weight. Fig. 1b presents situation when platforms are placed one on the top of other, where platform is stabilized on the edge of angles, rolls hide in prepared pockets stabilizing whole system. Inside profiles were introduced shields, which protects rolls during removal of pallets from the stack through the shorter edge. This construction allows designed palettes to be transported by the forklift with smaller fork spacing. Pockets on the long side does not introduce any limitations in this aspect.

It was assumed that platform will be strained with standard tanks, with outer diameter of 800 or $900 \mathrm{~mm}$. The maximum weight of the tank is $2400 \mathrm{~kg}$.

Mechanical properties of construction material applied in Autodesk Inventor are presented in Tab. 1. It is Alloy Steel S235JR+N.

Tab. 1: Properties of structural low-alloy steel S235JR+N.

\begin{tabular}{cc}
\hline Young's modulus & $210 \mathrm{GPa}$ \\
\hline Poisson's ratio & 0.3 \\
\hline Kirchhoff module & $80000 \mathrm{MPa}$ \\
\hline Density & $7.85 \mathrm{~g} / \mathrm{cm}^{3}$ \\
\hline Plastic range $R_{e}$ & $235 \mathrm{MPa}$ \\
\hline Tensile strength & $360 \mathrm{MPa}$ \\
\hline
\end{tabular}

\section{Numerical model}

FEM calculations were carried out in statistical analysis model. Coefficient of welded joints has been applied as value 1. Basement of model has been bond in stationary manner. For simulation purposes the value of gravity was assumed as $9810 \mathrm{~mm} / \mathrm{s}^{2}$. Gravity is marked with red arrow in Fig 2a. A total of 180 geometric contacts bonding the elements of the model were indicated on the structure. All joins were made as fillet welds with a width of $4 \mathrm{~mm}$. The total length of all fillet welds in the construction was $875 \mathrm{~mm}$, no discontinuities were used. The value of loading force is $50000 \mathrm{~N}$. It is transferred to construction through 8 points, which are roller supports, which is base for rolls that support stored tank. Because of its big dimensions (diameter of tank - $900 \mathrm{~mm}$ - is over $50 \%$ larger than distance between wheels of pallet) transferred load works in the direction that only slightly deviates from y-axis. Therefore, for simplicity load value is focused along this axis. Load that comes from tank was presented as yellow axes in Fig 2a. For creation of FEM elements mesh mean value of single element was set as 0.035 . The 
value of gradation coefficient was set to 1.5 , and none of the model angles exceed 60 degree. These parameters produced model grid from 614236 elements and 338873 nodes. Construct with mesh grid is shown in Fig $2 b$.
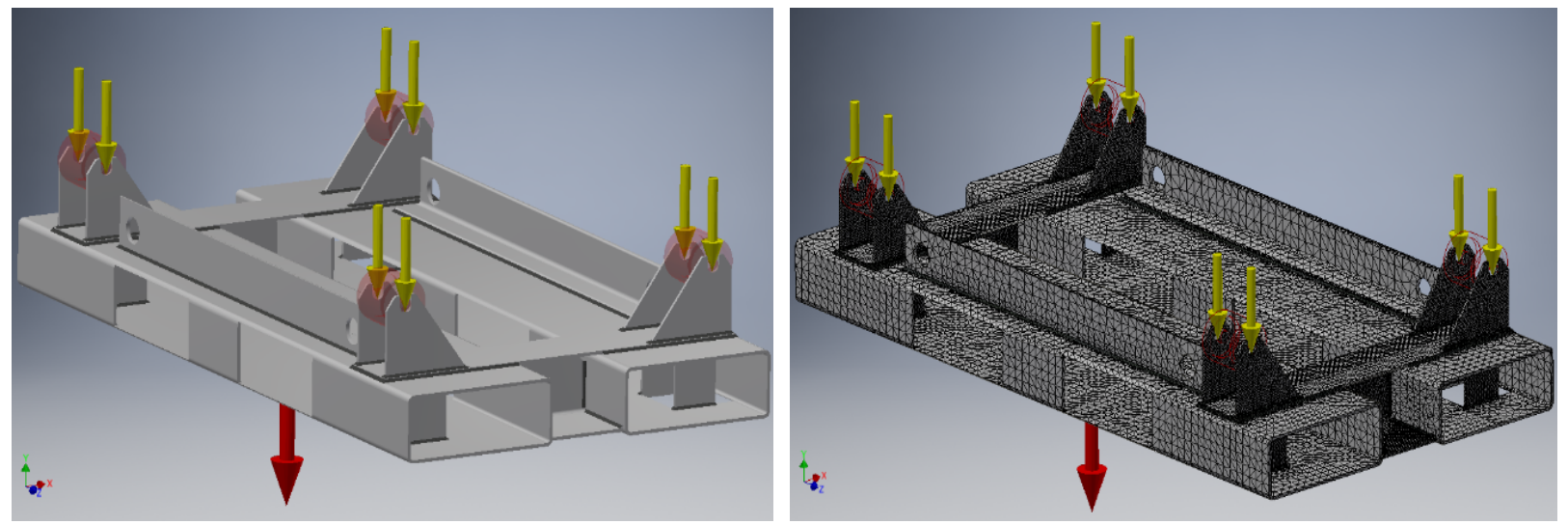

Fig. 2: a) CAD model of the fastening construction with marked loads, b) generated mesh model.

\section{Result analysis}

Analyzing the pallet, design takes into account both the palette itself, and the shaft on which the roll is suspended on a pallet holding tank. For simulation purposes, a roller was modelled with uniform diameter $20 \mathrm{~mm}$ along whole $100 \mathrm{~mm}$ length. Fig. 3 presents obtained stress maps respectively for whole construction (a) and the element most exposed to destruction i.e. roller (b).
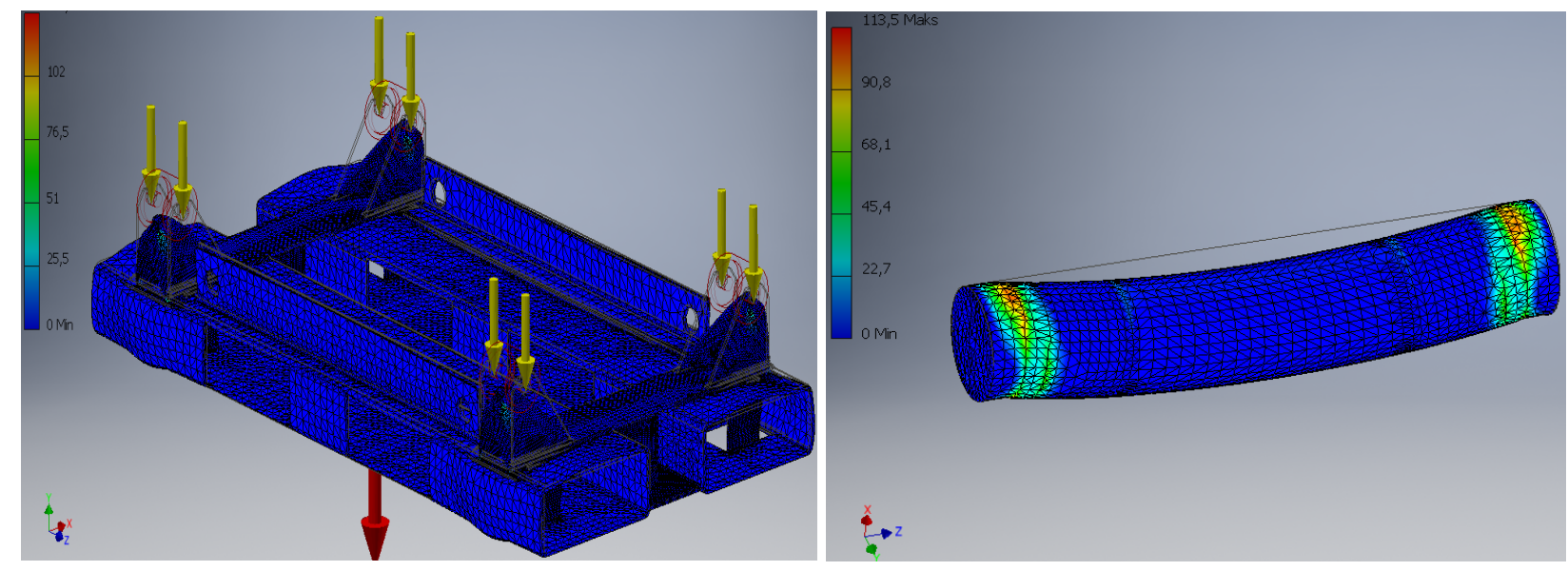

Fig. 3: Map of the reduced stress for: a) the fastening construction, b) roller.

Tab 2 presents results of numerical strength analysis.

Taking into account the below values, it is clear that none of the occurring stresses exceed the yield criterion of structural low - alloy steel used. Using equation:

$$
\frac{R_{e}}{\sigma_{\text {red }}}>1.5
$$

it was checked whether the condition regarding the safety factor was met.

The highest obtained value of reduced stresses was $127.548 \mathrm{MPa}$. In relation to it, the apparent yield strength of the material used has a value of $235 \mathrm{MPa}$ and has a safety factor of 1.84 . Also, value of reduced stress $117,742 \mathrm{MPa}$ obtained for the roller and compared to yield criterion of applied material showed safety value of 1.85 . Thus, the optimized design meets the previously described requirement of ADR 6.7.3.2 2017. 
Tab. 2: Results of numerical strength analysis.

\begin{tabular}{lcccc}
\hline & \multicolumn{2}{c}{ the fastening construction } & \multicolumn{2}{c}{ roller } \\
\cline { 2 - 5 } & minimum & maximum & minimum & maximum \\
\hline normal stresses $\sigma_{\mathrm{x}}$ & $-53.487 \mathrm{MPa}$ & $34.032 \mathrm{MPa}$ & $-148.516 \mathrm{MPa}$ & $149.228 \mathrm{MPa}$ \\
\hline normal stresses $\sigma_{\mathrm{y}}$ & $-126.493 \mathrm{MPa}$ & $27.402 \mathrm{MPa}$ & $-80.653 \mathrm{MPa}$ & $83.962 \mathrm{MPa}$ \\
\hline normal stresses $\sigma_{\mathrm{z}}$ & $-14.764 \mathrm{MPa}$ & $15.151 \mathrm{MPa}$ & $-131.336 \mathrm{MPa}$ & $128.314 \mathrm{MPa}$ \\
\hline shear stress $\tau_{\mathrm{xy}}$ & $-29.964 \mathrm{MPa}$ & $32.0326 \mathrm{MPa}$ & $-36.072 \mathrm{MPa}$ & $34.478 \mathrm{MPa}$ \\
\hline shear stress $\tau_{\mathrm{xz}}$ & $-15.964 \mathrm{MPa}$ & $15.846 \mathrm{MPa}$ & $-48.303 \mathrm{MPa}$ & $47.982 \mathrm{MPa}$ \\
\hline shear stress $\tau_{\mathrm{yz}}$ & $-20.887 \mathrm{MPa}$ & $19.2198 \mathrm{MPa}$ & $-22.904 \mathrm{MPa}$ & $23.117 \mathrm{MPa}$ \\
\hline reduced stress $\sigma_{\mathrm{red}}$ & $0.00000017 \mathrm{MPa}$ & $127.548 \mathrm{MPa}$ & $0.000831123 \mathrm{MPa}$ & $117.742 \mathrm{MPa}$ \\
\hline displacement along & $-0.026539 \mathrm{~mm}$ & $0.026397 \mathrm{~mm}$ & $-0.013575 \mathrm{~mm}$ & $0.000196 \mathrm{~mm}$ \\
\hline X axis & $-0.024139 \mathrm{~mm}$ & $0.006899 \mathrm{~mm}$ & $-0.000439 \mathrm{~mm}$ & $0.000438 \mathrm{~mm}$ \\
\hline $\begin{array}{l}\text { displacement along } \\
\text { Y axis }\end{array}$ & $-0.030744 \mathrm{~mm}$ & $0.030778 \mathrm{~mm}$ & $-0.005191 \mathrm{~mm}$ & $0.005192 \mathrm{~mm}$ \\
\hline \begin{tabular}{l} 
displacement axis \\
\hline
\end{tabular}
\end{tabular}

\section{Conclusions}

As a result of the bi-selective optimization, a pallet with a weight of $77 \mathrm{~kg}$ and the following dimensions was obtained: length $1200 \mathrm{~mm}$, width $625 \mathrm{~mm}$, height $250 \mathrm{~mm}$. The thickness of sheets and profiles used in the pallet construction was $5 \mathrm{~mm}$. This dimension takes into account the requirements for the use of forklifts, as described in EN 14208. The cost of its production was estimated at PLN 1550. However, due to the large number of welded joints and cut-outs, which reduced the mass of the entire structure, the pallet's time of manufacture was estimated at approximately 7.5 hours.

\section{References}

Ashby, M., Shercliff, H. and Cebon, D. (2007) Materials: Engineering, Science, Processing and Design. Butterworth - Heinemann is an imprint of Elsevier.

ADR 6.7.3.2 (2017) European Agreement concerning the International Carriage of Dangerous Goods by Road. Requirements for the design, construction, inspection and testing of portable tanks intended for the carriage of non-refrigerated liquefied gases.

EN 14208 (2004) Transportable gas cylinders - Specification for welded gas drums up to 3000 litre capacity for the transport of gases- design and construction.

Jureczko, M. (2013) Multidisciplinary optimization of wind turbine blades with respect to minimize vibrations. In: Recent advances in composite materials for wind turbine blades. Editor Brahim Attaf: Chapter 8 p. 129-146. The World Academic Publishing Co., Ltd. www.academicpub.org/amsa/.

Kim, I. Y. and Wek, O. L. (2005) Adaptive weighted-sum method for bi-objective optimization: Pareto front generation, Structural Multidisciplinary Optimization, vol. 29, pp. 149-158.

Mindur, L., Mindur, M. and Wielądek, A. (2002) Współczesne technologie transportowe. Wydawnictwo ITeE, Warszawa.

Pałkowski, Sz. (2009) Konstrukcje stalowe: Wybrane zagadnienia obliczania i projektowania. Wydawnictwo Naukowe PWN, Warszawa. 